Cell Research (2003); 13(5):385-391

http://www.cell-research.com

\title{
Intermittent hypoxia attenuates ischemia/reperfusion induced apoptosis in cardiac myocytes via regulating Bcl-2/Bax expression
}

\author{
Jian Wen Dong1, Hai Feng Zhu1, Wei Zhong Zhu1, Hai Lei Ding1, Tie Min Ma2, Zhao Nian Zhou1* \\ 1 Laboratory of Hypoxic Cardiovascular Physiology, Shanghai Institutes for Biological Sciences, Chinese Academy of \\ Sciences, Shanghai 200031, China.E-mail:znzhou@server.shcnc.ac.cn \\ 2 Department of Physiology and Pathophysiology, Health Science Center Peking University, Beijing 100083, China.
}

\begin{abstract}
Intermittent hypoxia has been shown to provide myocardial protection against ishemia/reperfusion-induced injury. Cardiac myocyte loss through apoptosis has been reported in ischemia/reperfusion injury. Our aim was to investigate whether intermittent hypoxia could attenuate ischemia/reperfusion-induced apoptosis in cardiac myocytes and its potential mechanisms. Adult male Sprague-Dawley rats were exposed to hypoxia simulated $5000 \mathrm{~m}$ in a hypobaric chamber for $6 \mathrm{~h}$ /day, lasting 42 days. Normoxia group rats were kept under normoxic conditions. Isolated perfused hearts from both groups were subjected to $30 \mathrm{~min}$ of global ischemia followed by $60 \mathrm{~min}$ reperfusion. Incidence of apoptosis in cardiac myocytes was determined by terminal deoxynucleotidyl transferase mediated dUTP nick end labeling (TUNEL) and DNA agarose gel electrophoresis. Expressions of apoptosis related proteins, Bax and Bcl-2, in cytosolic and membrane fraction were detected by Western Blotting. After ischemia/reperfusion, enhanced recovery of cardiac function was observed in intermittent hypoxia hearts compared with normoxia group. Ischemia/ reperfusion-induced apoptosis, as evidenced by TUNEL-positive nuclei and DNA fragmentation, was significantly reduced in intermittent hypoxia group compared with normoxia group. After ischemia/reperfusion, expression of Bax in both cytosolic and membrane fractions was decreased in intermittent hypoxia hearts compared with normoxia group. Although ischemia/reperfusion did not induce changes in the level of Bcl-2 expression in cytosolic fraction between intermittent hypoxia and normoxia groups, the expression of Bcl-2 in membrane fraction was upregulated in intermittent hypoxia group compared with normoxia group. These results indicated that the cardioprotection of intermittent hypoxia against ischemia/reperfusion injury appears to be in part due to reduce myocardial apoptosis. Intermittent hypoxia attenuated ischemia/reperfusion-induced apoptosis via increasing the ratio of Bcl-2/Bax, especially in membrane fraction.
\end{abstract}

Keywords: intermittent hypoxia, apoptosis, cardiac myocytes, Bax, Bcl-2.

\section{INTRODUCTION}

Intermittent hypoxia, or periodic exposure to hypoxia interrupted by return to normoxia or less hypoxic conditions, occurs in many circumstances[1]. Many studies showed that intermittent hypoxia might have the cardioprotective effects similar to those observed in ischemic preconditioning[2-8]. A number of studies have

*Correspondence: Prof. Zhao Nian ZHOU, Laboratory of Hypoxic Cardiovascular Physiology, Shanghai Institutes for Biological Sciences, Chinese Academy of Sciences, 320 Yueyang Road, Shanghai 200031, China.

Tel: 86-21-5492-0305, Fax: 86-21-5492-0306

E-mail: znzhou@server.shcnc.ac.cn

Received March-4-2003 Revised Aug-11-2003 Accepted Sep-15-2003 attempted to define the mechanisms of this phenomenon and several potential factors have been proposed to be involved in the protective mechanism afforded by intermittent hypoxia[3,5-7,9-11], however, the precise mechanisms underlying the protective effects of intermittent hypoxia on ischemic hearts are far from clear.

Apoptosis, a form of death characterized by cell shrinkage, plasma membrane blebbing, chromatin condensation and genomic DNA fragmentation, is essential for development and maintenance of tissue homeostasis. On the other hand, apoptosis has been implicated in many diseases such as congestive heart failure and ischemic injury. Although a large portion of the cell loss during cardiac ischemia and reperfusion occurs through 
necrosis, there were increasing evidences that cardiac myocyte death may also occur through apoptosis[12-15]. However, little investigation has been conducted to determine whether the cardioprotective effect afforded by intermittent hypoxia relates to reduction in apoptosis during ischemia/reperfusion.

The objective of this study was therefore to determine whether intermittent hypoxia could protect the rat heart against ischemia/reperfusion-induced apoptosis. Since Bcl-2 family of proteins plays a major role in determining the ultimate sensitivity or resistance of cells to myriad stimulus and insults that induce apoptosis[22-24], we also examined the effects of intermittent hypoxia on proteins of Bcl-2 family.

\section{METHODS}

\section{Animal model}

Adult male Sprague-Dawley rats, originally weighting 100-130 g and finally weighting 340-380 g, were exposed to intermittent hypoxia simulated in a hypobaric chamber for $6 \mathrm{~h} /$ day, lasting 42 days. Barometric pressure $\left(\mathrm{P}_{\mathrm{B}}\right)$ was lowered stepwise to the level equivalent to an altitude of $5000 \mathrm{~m}\left(\mathrm{P}_{\mathrm{B}}=404 \mathrm{mmHg} ; \mathrm{Po}_{2}=84 \mathrm{mmHg}\right)$. Age-matched normoxia group of animals was kept at normoxic condition. All animals had free access to water and standard laboratory diet.

\section{Perfusion of the hearts}

After the last hypoxic exposure, the rats were anesthetized with sodium pentobarbital $(40 \mu \mathrm{g} / \mathrm{kg}$, i.p.). Hearts were rapidly excised and mounted on a Langendorff apparatus perfusing with non-recirculation Krebs-Henseleit buffer at constant pressure $(80 \mathrm{mmHg})$. KrebsHenseleit buffer solution contains (in $\mathrm{m} M$ ): $\mathrm{NaCl} 118.0, \mathrm{KCl}$ 4.7, $\mathrm{CaCl}_{2}$ 2.5, $\mathrm{MgSO}_{4} 1.2, \mathrm{NaHCO}_{3} 25.0, \mathrm{KH}_{2} \mathrm{PO}_{4} 1.2$, sodium pyruvate 2.0, Na2EDTA 0.026 and glucose $11.0, \mathrm{pH} 7.4$ continuously gassed with $95 \% \mathrm{O}_{2} / 5 \% \mathrm{CO}_{2}$ and maintained at $37^{\circ} \mathrm{C}$. A latex balloon filled with degassed distilled water was inserted into the left ventricle via the mitral valve to record isovolumic left ventricular pressure through a pressure transducer (Gould P23Db). Left ventricular end-diastolic pressure (LVEDP) was adjusted to 5-10 $\mathrm{mmHg}$ during initial equilibration period. Heart rate (HR), left ventricular systolic pressure (LVSP), LVEDP, coronary flow (CF) and the peak rate of pressure developed $( \pm \mathrm{dp} / \mathrm{dtmax})$ were collected with PowerLab system (AD Instrument ltd, Australia).

After an equilibration period of $15 \mathrm{~min}$, hearts from normoxia or intermittent hypoxia group were submitted to normal perfusion for $90 \mathrm{~min}(\mathrm{P})$ and $30 \mathrm{~min}$ global ischemia followed by $60 \mathrm{~min}$ reperfusion (I/R) respectively. During the global ischemia period, hearts were embedded in a bath of Krebs-Henseleit buffer solution maintaining at $37^{\circ} \mathrm{C}$. Reperfusion values were expressed as percentages of this preischemic value for each experiment.

\section{DNA Fragmentation analysis}

DNA fragmentation was studied by agarose gel electrophoresis. rozen tissue sample were minced and homogenized in lysis buffer (in mM: Tris- $\mathrm{HCl} 10, \mathrm{NaCl} 150$ and EDTA 10, $\mathrm{pH} 8.0$ ) at $0^{\circ} \mathrm{C}$. The homogenate was then treated with $100 \mu \mathrm{g} / \mathrm{ml}$ proteinase K (MERCK, Germany) and $0.1 \%$ SDS for $90 \mathrm{~min}$ at $560 \mathrm{C}$. The DNA was extracted with phenol and chloroform followed by ethanol precipitation. The pellet was resuspended in TE buffer $(10 \mathrm{mM} / \mathrm{L}$ Tris- $\mathrm{HCl}, \mathrm{pH} 8.0$ and $1 \mathrm{mM}$ EDTA) and treated with RNase ( MERCK, Germany) for $2 \mathrm{~h}$ at $37^{\circ} \mathrm{C}$. The concentration of DNA was measured through spectrophotometry, and $10 \mu \mathrm{g}$ of each DNA sample was electrophoretically resolved on a $2 \%$ agarose gel containing $0.5 \mu \mathrm{g} / \mathrm{ml}$ ethidium bromide. DNA was visualized and photographed with a UV transilluminator.

\section{TdT-mediated dUTP nick end labeling (TUNEL)}

At the end of the protocols, the hearts were sectioned and fixed up in neutral formalin (10\% formaldehyde in PBS, $\mathrm{pH} 7.4)$. The TUNEL protocol is based on the preferential labeling of terminal deoxynucleotidyl transferase at the 3'-OH ends of DNA[25]. In brief, the fixed transverse left ventricular slices were embedded in paraffin and 4-5 mm thick sections were deparaffinized, subsequently incubated with $50 \mu \mathrm{g} / \mathrm{ml}$ proteinase $\mathrm{K}$ for $15 \mathrm{~min}$ at $37^{\circ} \mathrm{C}$, and endogenous peroxidase was inactivated by a treatment of $3 \%$ hydrogen peroxide for $5 \mathrm{~min}$. They were incubated with terminal deoxynucleotidyl transferase (Roche Molecular Biochemicals, Germany) for $1.5 \mathrm{~h}$ at $37^{\circ} \mathrm{C}$. After the end-labeling, sections were incubated with anti-digoxigenin peroxidase for $1 \mathrm{~h}$ at room temperature. For the color development, sections were immersed in NBT for $30 \mathrm{~min}$ in dark.

Positive (by pretreating the sections with $1 \mathrm{U} / \mathrm{ml}$ DNAse I for 15 min at $37^{\circ} \mathrm{C}$ ) and negative (by omitting dUTP or TdT) controls were run for every block. For quantitative analysis, TUNEL-positive cells in five different slides from different hearts were counted in a doubleblind ways. The data was expressed as number of TUNEL-positive myocytes per slide.

\section{Western blot analysis of Bax and Bcl-2 protein}

For immunoblotting of Bax and Bcl-2 in cytosolic and membrane fractions, hearts were homogenized and extracted in isotonic sucrose buffer A ( in mM: Sucrose 250, Tris.Cl 20, Na3VO4 0.03, MgCl2 2. 0, EDTA 2.0, EGTA 0.5, DTT 1, PMSF 2, Protease Inhibitor Cocktail $0.02 \%(\mathrm{v} / \mathrm{v}), \mathrm{pH} 7.4)$. Samples were centrifuged ( $500 \mathrm{~g})$ to pellet nuclei, unbroken cells. The supernatant were centrifuged at 100,000 g for $60 \mathrm{~min}$ at $4 \mathrm{oC}$ to separate the membrane fraction (pellet) from the cytosolic fraction (supernatant). The membrane fraction was resuspended with $0.1 \%$ Triton X-100 in buffer A for $30 \mathrm{~min}$, then centrifuged at $100,000 \mathrm{~g}$ for $60 \mathrm{~min}$ at $4 \mathrm{oC}$. The protein content of each fraction was determined by the BioRad Bradford assay.

After boiling for $10 \mathrm{~min}$, equivalent amounts of protein $(50 \mu \mathrm{g})$ were resolved by $12 \%$ SDS-PAGE, electroblotted onto PVDF membrane and immunoreacted overnight with Bcl-2 and Bax antibodies (Sigma, USA), followed by $2 \mathrm{~h}$ incubation with the secondary antibody (Sigma, USA) conjugated with HRP. Chemiluminescent signals were generated by the addition of the ECL reagents (Amersham Pharmacia Inc.) and detected on radiographic film. The Bcl-2 was detected as a $26-\mathrm{kDa}$ band and the Bax protein was detected as a $21-$ $\mathrm{kDa}$ band. The scanned image was imported into Adobe Photoshop software, scanning densitometry was used for semiquantitative analy- 
sis of the data.

\section{Statistical analysis}

Data were expressed as mean \pm SE. Comparisons were performed by paired t test within group. Among groups, comparisons were performed by ANOVA with multiple comparisons or $t$ test when appropriate. A difference of $\mathrm{P}<0.05$ was considered significant.

\section{RESULTS}

\section{Hemodynamic data}

To assess whether IH protected hearts against ischemia/reperfusion insult, the contractile parameter was recorded during ischemia/reperfusion. There were no significant differences in the values of contractile parameters between the two groups at baseline and extended perfusion periods (data not shown), however, intermittent hypoxia training dramatically improved the postischemic contractile force during reperfusion. As shown in Fig 1, the maximum recovery of $+\mathrm{dp} / \mathrm{dtmax}$ and $-\mathrm{dp} /$ dtmax were $16.8 \pm 2.8 \%$ and $18.6 \pm 2.7 \%$ of the stabilization period respectively in the normoxic hearts, while they were improved to $41.0 \pm 2.6 \%(\mathrm{P}<0.01)$ and 38.2 $\pm 1.9 \%(\mathrm{P}<0.01)$ respectively in intermittent hypoxia
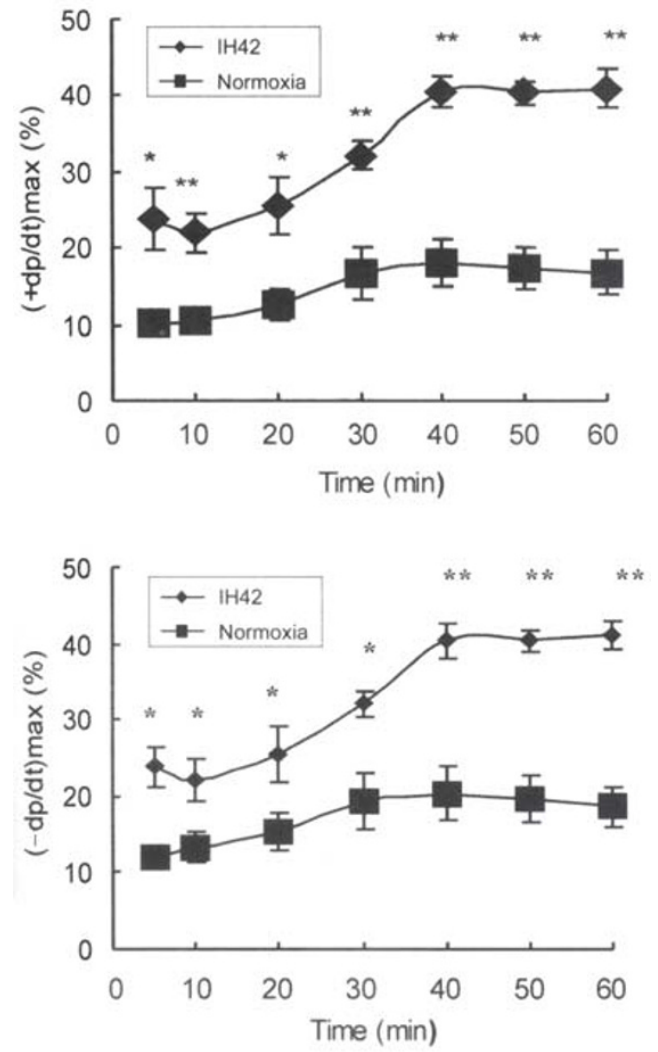

Fig 1. Recovery of peak rate of pressure development ( $\pm \mathrm{dp} / \mathrm{dtmax})$ during reperfusion after $30 \mathrm{~min}$ global ischemia in the normoxia and intermittent hypoxia groups. Values are expressed as percentage of the stabilization period (mean $\pm \mathrm{SE}, \mathrm{n}=6$ ). $* \mathrm{P}<0.05$, ${ }^{*} \mathrm{P}<0.01$ vs normoxia. hearts. It suggested that the resistance to reperfusion dysfunction of the hearts from intermittent hypoxia was greatly increased.

\section{Effects of intermittent hypoxia on myocardial apoptosis}

To elucidate the role of myocardial apoptosis in the functional improvement after ischemia/reperfusion induced by IH, apoptosis was determined by DNA fragmentation (Fig 2) and TUNEL-positive nuclei (Fig 3). In myocardial tissue from normoxic or intermittent hypoxia hearts continuously perfused for $2 \mathrm{~h}$, no DNA fragmentation was detected. The formation of DNA fragmentation was clearly detected in ischemia/reperfusion hearts from normoxia rats, which indicated the occurrence of apoptosis. In contrast, no DNA fragmentation was detected in ischemia/reperfusion hearts from intermittent hypoxia rats. Consistent with the absence of DNA fragmentation, few TUNEL-positive was present in continuously perfused hearts from both groups. Moreover, after $30 \mathrm{~min}$ of ischemia and $60 \mathrm{~min}$ of reperfusion, the number of TUNEL-positive myocytes was greatly decreased in intermittent hypoxia group compared with that in normoxic group (8.6 \pm 1.9 /slide vs $29.4 \pm 7.2$ /slide, $P$ $<0.01)$. These results demonstrated that apoptosis in the myocardium after ischemia/reperfusion was attenuated by intermittent hypoxia.

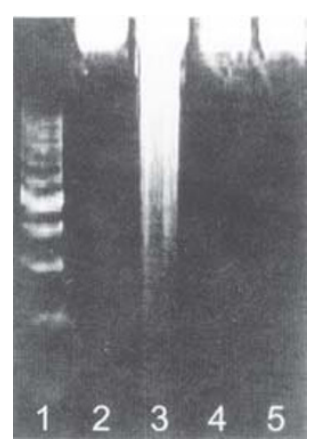

Fig 2. Representative DNA fragmentation result of 3 independent experiments using agarose gel electrophoresis. Lane 1, marker; Lane 2, normal perfusion of normoxia group; Lane 3, ischemia/reperfusion of normoxia group; Lane 4, normal perfusion of intermittent hypoxia group (IH); Lane 5, ischemia/reperfusion of intermittent hypoxia group. DNA fragmentation pattern was seen in Lane 3. No fragmentation pattern was observed in Lane 5. 


\section{A}
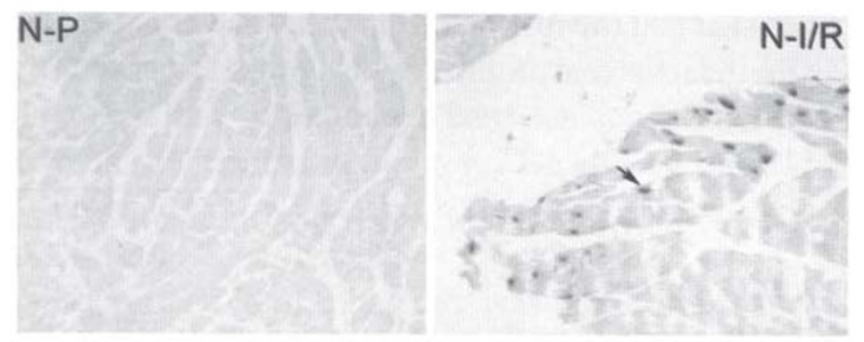

IH-P

IH-I/R

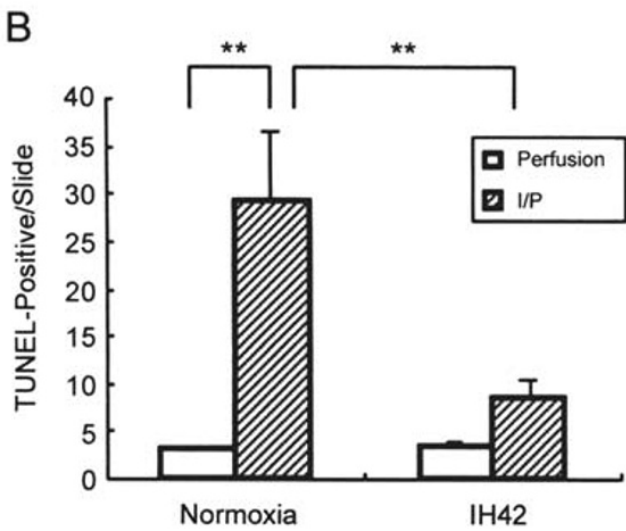

Fig 3. Evaluation of cardiomyocyte apoptosis using terminal dUTP nick end labeling (TUNEL). (A) Representative photomicrographs showing apoptotic cardiomyocytes. Brown staining (TUNELpositive) indicates apoptotic myocytes (arrow). (B) Bar graph showing average number of cardiomyocytes undergoing apoptosis per slide. Results are expressed as mean $\pm \mathrm{SE}$ of five different rats per group. $\mathrm{N}$ represents normoxia group, $\mathrm{P}$ represents normal perfusion, $\mathrm{I} / \mathrm{R}$ represents $30 \mathrm{~min}$ ischemia and $60 \mathrm{~min}$ reperfusion, IH represents intermittent hypoxia group. $* * \mathrm{P}<0.01$

\section{Bax and Bcl-2 expression after myocardial ischemial} reperfusion

Because interaction of Bax and Bcl-2 played an important role in the regulation apoptosis, we want to establish whether the antiapoptotic effects conferred by intermittent hypoxia were due to altered expression of Bcl-2 family proteins. We further detected Bax and Bcl2 protein contents in cytosolic and membrane fraction by SDS-PAGE and immunoblotting with specific antibodies. No significant differences were observed in hearts con- tinuously perfused for 120 min between normoxia and intermittent hypoxia groups (data not shown). Changes in $\mathrm{Bax}$ and $\mathrm{Bcl}-2$ protein expression after ischemia and reperfusion were shown in Fig 4. Compared with normoxia group, intermittent hypoxia decreased Bax expression in both cytosolic $(54.1 \pm 9.6 \%, \mathrm{P}<0.05$ vs Normoxia group $101.0 \pm 8.9 \%$ ) and membrane fraction $(69.5 \pm 9.0 \%, \mathrm{P}<0.05$ vs Normoxia group $101.1 \pm 6.3 \%)$ from hearts subjected to ischemia and reperfusion. Although no significant increase in $\mathrm{Bcl}-2$ expression was detected in the cytosolic fraction between normoxia ( 89 . $0 \pm 12.8 \%)$ and intermittent hypoxia groups $(92.1 \pm 17$. $7 \%, \mathrm{P}>0.05)$, a significant increase in Bcl-2 expression was detected in the membrane fraction from ischemia/ reperfusion hearts in intermittent hypoxia group (145.3 $\pm 14.6 \%, \mathrm{P}<0.05)$ compared with normoxia group $(90.8$ $\pm 8.9)$. These results indicated that intermittent hypoxia increased the ratio of Bcl-2/Bax, especially in membrane fraction, after ischemia/reperfusion.
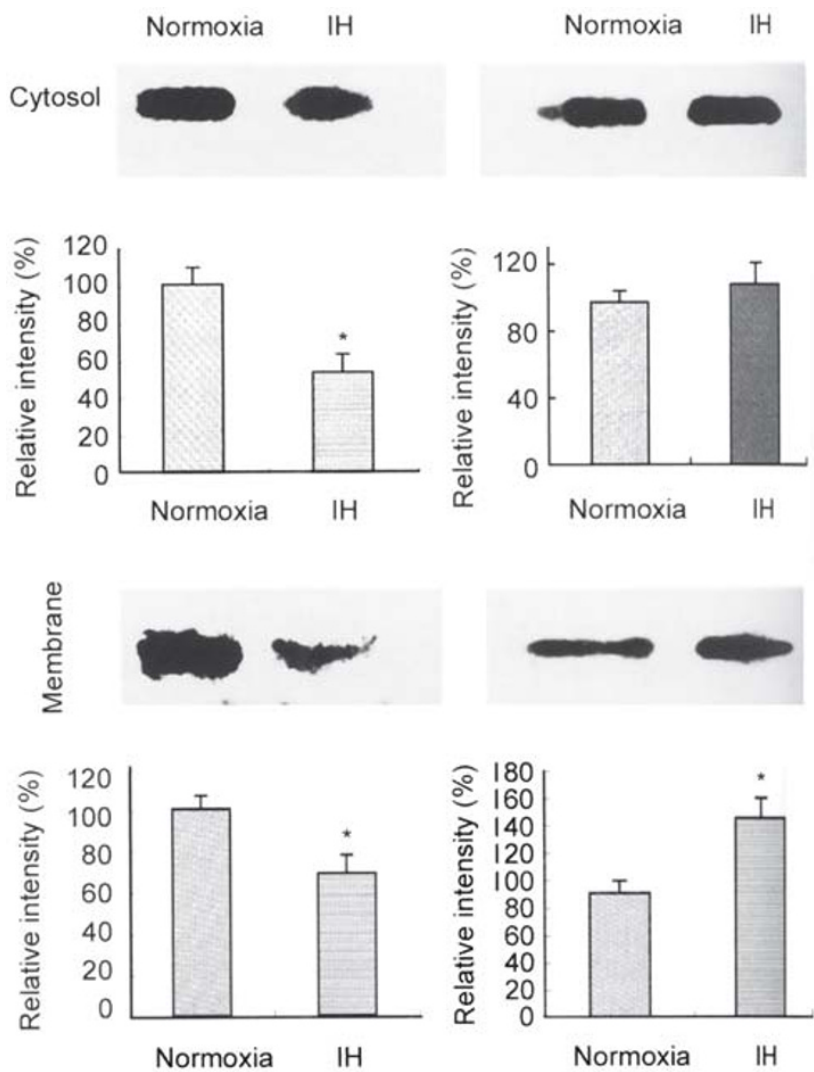

Fig 4. Expression of Bax and Bcl-2 protein in cytosolic and membrane fractions in ischemia/reperfusion hearts from normoxia and intermittent hypoxia (IH) groups. 


\section{DISCUSSION}

To our knowledge, our results provided the evidence that intermittent hypoxia significantly reduced apoptosis in the isolated perfused rat heart after ischemia/ reperfusion. Previous investigators have shown that intermittent hypoxia could protect against ischemia/ reperfusion injury[4-6,11], but no measure of apoptosis has been reported. Another finding in our study is that the antiapoptotic effect of intermittent hypoxia was due to regulate expression of $\mathrm{Bcl}-2 / \mathrm{Bax}$ protein.

Our hemodynamic data in perfused rat hearts showed that the resistance to reperfusion dysfunction of hearts from animals adapted to intermittent hypoxia was strikingly enhanced. These results are in agreement with those of Neckar et al[11], who demonstrated that long term intermittent hypoxia corresponding to $5000 \mathrm{~m}$ for $8 \mathrm{~h} /$ day, 5 days a week, for 24-32 days, increased the tolerance of rat hearts to ischemia/reperfusion. This was determined as improved recovery of post-ischemic contractile function and reduction in infarct size.

A large component of cell death during myocardial ischemia/reperfusion results from cellular necrosis. Furthermore, recent evidences suggested that apoptosis contributes in part to overall myocyte cell death during the reperfusion period[12-16]. Ischemic preconditioning, a phenomenon whereby exposure of the hearts to brief periods of ischemia, makes the hearts tolerant to subsequent lethal ischemic injury, has been shown in vivo or in vitro to inhibit apoptosis in the heart or cardiomyocytes subjected to ischemia/reperfusion[17-21]. Similar to ischemic preconditioning, the results from DNA fragmentation electrophoresis and TUNEL-positive nuclei count in the present study showed that IH adaptation was effective in alleviating the cardiac apoptosis induced by ischemia/reperfusion.

Apoptosis is governed by a number of regulatory genes mediated by apoptosis signals. Among them, the Bcl-2 family of proteins constitutes a central checkpoint. The Bcl-2 family consists of both cell death promoters and cell death preventers[22-24]. Proapoptotic proteins include Bax, Bak, Bcl-XS, Bad, Bik, Bim, Bid, Hrk and Bok, whereas anti-apoptotic proteins include Bcl-2, Bcl$\mathrm{XL}, \mathrm{Mcl}-1, \mathrm{~A} 1 / \mathrm{Bfl}-1$. The ratio of anti- to pro-apoptotic molecules such as Bcl-2/Bax determines the response to a death signal. Bcl-2, a $26 \mathrm{kDa}$ protein, is predominantly localized to the cytoplasmic face of the mitochondria outer membrane, endoplasmic reticulum, and nuclear envelope. Bcl-2 seems to prevent apoptosis induced by many stimuli, for example, irradiation, FasL[26], TRAIL [27] and deprivation of growth factor, and it has been shown to suppress cytochrome c (cyt.c) efflux from mitochondria, inhibit calcium release from the endoplasmic reticulum[24,28,29]. Others have speculated that Bcl2 regulates the generation of reactive oxygen radical since $\mathrm{Bcl}-2$ is able to attenuate cell death induced by oxidative damaging agents[30,31]. Bax, which normally resides in the cytosol, translocates to mitochondria when triggered by certain stimuli, enables its active configuration as a dimerized intergral mitochondrial membrane protein[32, 33]. Translocated Bax has been shown to induce cyt.c release and followed by caspase activation [32].

The antiapoptotic role of Bcl-2 is well documented in myocardium. It was demonstrated that genetic modification of the myocardium with the anti-apoptotic human Bcl-2 gene conferred myocardial protection against ischemia/reperfusion-induced apoptosis [34,35]. Furthermore, several studies have reported a reduction of apoptosis by ischemic preconditioning via altering the expression of Bcl-2 and/or Bax protein, thus increased the ratio of $\mathrm{Bcl}-2 / \mathrm{Bax}$ protein in preventing the progression of apoptosis in myocardium after ischemia and reperfusion[20,21].

In the present study, it was shown that apoptosis occurred in perfused rat hearts subjected to $30 \mathrm{~min}$ of global ischemia followed by $60 \mathrm{~min}$ of reperfusion. The presence of apoptotic cells and DNA fragmentation in cardiac myocytes were completely abolished by intermittent hypoxia. Although there were no significant changes in the expression of Bcl-2 or Bax under baseline perfusion, after ischemia/reperfusion, the expression of Bax in both the membrane and cytosolic fraction from the intermittent hypoxia hearts was decreased. The expression of Bcl-2 was increased only in the membrane fraction from intermittent hypoxia hearts. Since Bcl-2 is an intracellular membrane protein most convincingly localized at mitochondria, endoplasmic reticulum and nuclear membrane, and the main target of the Bcl-2 and Bax is membrane, our present study suggested that the increased ratio of Bcl-2/Bax, especially in the membrane fraction by intermittent hypoxia plays a pivotal role in its ability to attenuate ischemia/reperfusion-induced apoptosis. These results are consistent with the absence of apoptosis in myocardium subjected to ischemia/ reperfusion after ischemic preconditioning[20,21]. 
Moreover, Riva et al[36] exposed adult rats to chronic hypobaric hypoxia for 21 days and found that chronic hypoxia did modify the expression of Bcl-2 and change the ratio of Bcl-2 over Bax.

Bax forms large channels in the outer membrane of mitochondria, which liberate cyt.c. Released cyt.c in conjunction with the cytosolic factor Apaf-1 and caspase 9 , may stimulate the conversion of procaspase- 3 to activate protease, but Bcl-2 may be able to prevent channel formation by $\operatorname{Bax}[22-24,32,33]$. This could account for our above results that increased $\mathrm{Bcl}-2 / \mathrm{Bax}$ ratio could inhibit apoptosis. However, the possible involvement of cyt.c and caspase in intermittent hypoxia has not been reported so far.

In conclusion, the present study provided the primary evidence that the cardioprotective effects of intermittent hypoxia against ischemia/reperfusion may be partially due to its ability to inhibit ischemia/reperfusion-induced apoptosis. Furthermore, our data strongly suggest that intermittent hypoxia exerts its antiapoptotic effect via regulating $\mathrm{Bcl}-2 / \mathrm{Bax}$ proteins. The precise mechanism for the inhibition of myocardial ischemia/reperfusion injury and attenuation of apoptosis afforded by intermittent hypoxia requires further investigation.

\section{ACKNOWLEDGEMENTS}

The study was supported by grants from National Natural Science Foundation of China, and the Science and Technology committee of Shanghai Municipality (02JC14038).

\section{REFERENCES}

1 Powell FL, Garcia N. Physiological effects of intermittent hypoxia. High altitude Medicine \& Biology 2000; 1(2):125-36.

2 Meerson FZ, Gomzakov OA, Shimkovich MV. Adaptation to high altitude hypoxia as a factor preventing development of myocardial ischemic necrosis. Am J Cardiol 1973; 31(1):30-4.

3 Zhong N, Zhang Y, Zhu HF, Wang JC, Fang QZ, Zhou ZN. Myocardial capillary angiogenesis and coronary flow in ischemia tolerance rat by adaptation to intermittent high altitude hypoxia. Acta Pharmacol Sin 2002; 23(4):305-10.

4 Meerson FZ, Ustinova EE, Orlova EH. Prevention and elimination of heart arrhythmias by adaptation to intermittent high altitude hypoxia. Clinic Cardiology 1987; 10(12):783-9.

5 Asemu G, Papousek F, Ostadal B, Kolar F. Adaptation to high altitude hypoxia protects the rat heart against ischemia-induced arrhythmias. Involvement of mitochondrial KATP channel. J Mol Cell Cardiol 1999; 31(10):1821-31.

6 Zhang Y, Zhong N, Zhu HF, Zhou ZN. Antiarrhythmic and antioxidative effects of intermittent hypoxia exposure on rat myocardium. Acta Physiol Sin 2002; 52(2):89-92.

7 Mohan RM, Golding S and Paterson DJ. Intermittent hypoxiaimproves atrial tolerance to subsequent anoxia and reduces stress protein expression. Acta Physiol Scand 2001; 172:8995.

8 Milano Giuseppina, Corno AF, Lippa S, et al. Chronic and intermittent hypoxia induce different degrees of myocardial tolerance to hypoxia-induced dysfunction. Exp Biol Med (Maywood) 2002; 227(6):389-97.

9 Zhong N, ZhangY, Fang QZ, Zhou ZN. Intermittent hypoxia exposure-induced hear-shock protein 70 expression increases resistance of rat heart to ischemic injury. Acta Pharmacol Sin 2000; 21(5):467-72

10 Zhang Y, Zhong N, Zhou ZN. Effects of intermittent hypoxia on action potential and contraction in non-ischemic and ischemic rat papillary muscle. Life Sciences 2000; 67(20):2465_71.

11 Neckar J, Szarszoi O, Koten L, et al. Effects of mitochondrial KATP modulators on cardioprotection induced by chronic high altitude hypoxia in rats. Cardiovas Res 2002; 55(3):567-75.

12 Gottlieb RA, Burleson KO, Kloner RA, Babior BM, Engler RL. Reperfusion injury induces apoptosis in rabbit cardiomyocytes. J Clin Invest 1994; 94(4):1621-8.

13 Fliss H and Grattinger D. Apoptosis in ischemic and reperfused rat myocardium. Circ Res 1996; 79:949-56.

14 Kajstura J, Cheng W, Reiss K, et al. Apoptotic and necrotic myocyte cell deaths are independent contributing variables of infarct size in rats. Lab Invest 1996; 74:86-107.

15 Zhao ZQ, Nakamura M, Wang NP, et al. Reperfusion induces myocardial apoptotic cell death. Cardiovasc Res 2000; 45:651-60.

16 Olivetti G, Quaini F, Sala R, et al. Acute myocardial infarction in human is associated with activation of programmed myocyte cell death in the surviving portion of the heart. J Mol Cell Cardiol 1996; 28:2005-16.

17 Gottlieb RA, Gruol DL, Zhu JY, Engler RL. Preconditioning in rabbit cardiomyicytes. J Clin Invest 1996; 97:2391-8.

18 Maulik N, Yoshida T, Engelman RM, et al. Ischemic preconditioning attenuates apoptotic cell death associated with ischemia/ reperfusion. Mol Cell Biochem 1998; 186:139-45.

19 Piot CA, Martini JF, Bui SK et al. Ischemic preconditioning attenuates ischemia/reperfusion-induced activation of caspases and subsequent cleavage of poly(ADP-ribose) polymerase in rat heart in vivo. Cardiovasc Res 1999; 44:536-42.

20 Maulik N, Engelman RM, Rousou JA, et al. Ischemic preconditioning reduces apoptosis by upregulating anti-dearth gene Bcl2. Circulation 1999; 100(19 Suppl):II369-75.

21 Nakamura M, Wang NP, Zhao ZQ, et al. Preconditioning decreases Bax expression, PMN accumulation and apoptosis in reperfused rat heart. Cardiovasc Res 2000; 45:661-70.

22 Oltvai ZN, Milliman CL and Korsmeyer SJ. Bcl-2 heterodimerizes in vivo with a consered homolog, Bax, that accelerates programmed cell death. Cell 1993; 74:609-19.

23 Chao DT, Korsmeyer SJ. Bcl-2 family: regulators of cell death. Annu Rev Immunol 1998; 16:395-419.

24 Adams JM, Cory S. The Bcl-2 protein family: arbiters of cell survival. Science 1998; 281:1322-6. 
25 Wijsman JH, Jonker RR, Keijzer R, et al. A new method to detect apoptosis in paraffin sections: in situ end-labeling of fragmented DNA. J Histochem Cytochem 1993; 41(1):7-12.

26 Chang YC, and Xu YH. Expression of Bcl-2 inhibited Fas-mediated apoptosis in human hepatocellular carcinoma BEL- 7404 cells. Cell Res 2000; 10:233-42.

27 Guo BC and $\mathrm{Xu}$ YH. Bcl-2 over-expression and activation of protein kinase $\mathrm{C}$ suppress the trail-induced apoptosis in Jurkat T cells. Cell Res 2001; 11:101-6.

28 Foyouzi-Youssefi R, Arnaudeau S, Borner C, et al. Bcl-2 decreases the free $\mathrm{Ca} 2+$ concentration within the endoplasmic reticulum. Proc Natl Acad Sci USA 2000; 97:5723-8.

29 Zhang M, Zhang HQ, Xue SB. Effect of Bcl-2 and caspase-3 on calcium distribution in apoptosis of HL-60 cell. Cell Res 2000; 10: 213-20.

30 Bogdanov MB, Ferrante RJ, Mueller G, Ramos LE, Martinou JC, Beal MF. Oxidative stress is attenuated in mice overexpressing BCL-2. Neurosci Lett 1999; 262:33-6.

31 Hockenbery DM, Oltvai ZN, Yin XM, Milliman CL, Korsmeyer SJ. Bcl-2 functions in an antioxidant pathway to prevent apoptosis. Cell 1993; 75:241-51.

32 Saikumar P, Dong Z, Patel Y, et al. Role of hypoxia-induced Bax translocation and cytochrome $\mathrm{c}$ release in reoxygenation injury. Oncogene 1998; 17:3401-15.

33 Gross A, Jockel J, Wei MC and Korsmeyer S. Enforced dimerization of Bax results in its translocation, mitochondrial dysfunction and apoptosis. EMBO J 1998; 17:3878-85.

34 Brocheriou V, Hagege AA, Oubenaissa A, et al. Cardiac functional improvement by a human Bcl-2 transgene in a mouse model of ischemia/reperfusion injury. J Gene Med 2000; 2:326-33.

35 Chen ZY, Chua CC, Ho YS, Hamdy RC, Chua BHL. Overexpression of Bcl-2 attenuates apoptosis and protects against myocardial I/ $\mathrm{R}$ injury in transgenic mice. Am J Physiol 2001; 280:H2313-20.

36 Riva C, Chevrier C, Pasqual N, Saks V and Rossi A. Bcl-2/Bax protein expression in heart, slow-twitch and fast-twitch muscles in young rats growing under chronic hypoxia conditions. Mol and Cell Biochem 2001; 226:9-16.

37 Murry CE, Jennings RB, Reimer KA. Preconditioning with ischemia: a delay of lethal cell injury in ischemic myocardium. Circulation 1986; 74:1124-36. 